\title{
Early and Systematic Administration of Fibrinogen Concentrate in Postpartum Haemorrhage Following Vaginal Delivery: The FIDEL Randomized Controlled Trial.
}

Ducloy-Bouthors Ducloy-Bouthors ${ }^{1}$, Frederic Mercier $^{2}$, Jean-Marie Grouin ${ }^{3}$, Francoise Bayoumeu $^{4}$, Julien Corouge ${ }^{1}$, Agnes Le Gouez ${ }^{5}$, Thibaut Rackelboom ${ }^{6}$, Francoise Broisin ${ }^{7}$, Florence Vial $^{8}$, Aymeric Luzi ${ }^{9}$, FIDEL Working group ${ }^{10}$, Cyril Huissoud ${ }^{11}$, and Alexandre Mignon $^{12}$

${ }^{1}$ Centre Hospitalier Regional Universitaire de Lille

${ }^{2}$ Hopital Antoine-Beclere

${ }^{3}$ Inserm U1219, Population Health. Bordeaux, France

${ }^{4}$ Centre Hospitalier Universitaire de Toulouse

${ }^{5}$ Hospital Antoine-Beclere

${ }^{6}$ Hospital Cochin

${ }^{7}$ Hopital de la Croix-Rousse

${ }^{8}$ Centre Hospitalier Universitaire de Nancy

${ }^{9}$ Centre Hospitalier Universitaire de la Reunion

${ }^{10}$ Centre Hospitalier Universitaire de Lille

${ }^{11}$ Centre hospitalo universitaire de Lyon Croix-Rousse

${ }^{12}$ Hopital Cochin

September 10, 2020

\begin{abstract}
Objective: To assess the benefits and safety of early human fibrinogen concentrate (FC) in postpartum haemorrhage (PPH) management. Design: Multicentre, double-blind, randomized placebo-controlled trial. Setting:30 French hospitals. Population: patients with persistent PPH after vaginal delivery requiring a switch from oxytocin to prostaglandins. Methods: Within 30 min after introduction of prostaglandins, patients received either $3 \mathrm{~g}$ FC or placebo. Main outcome measures: Failure as composite primary efficacy endpoint: at least $4 \mathrm{~g} / \mathrm{dL}$ of haemoglobin decrease and/or transfusion of at least 2 units of packed red blood cells within $48 \mathrm{~h}$ following investigational medicinal product administration. Secondary endpoints: PPH evolution, need for haemostatic procedures, and maternal morbidity-mortality within $6 \pm 2$ weeks after delivery. Results: the intention-totreat analysis included 437 patients of which 224 received FC and 213 placebo. At inclusion, blood loss $(877 \pm 346 \mathrm{~mL})$ and plasma fibrinogen $(\mathrm{FG})(4.1 \pm 0.9 \mathrm{~g} / \mathrm{L})$ were similar in both groups (mean $\pm \mathrm{SD})$. Failure rates were $40.0 \%$ and $42.4 \%$ in the $\mathrm{FC}$ and placebo groups, respectively $(\mathrm{OR}=0.99)$ after adjustment on centre and baseline FG; $(95 \% \mathrm{CI}$ : [0.66;1.47]; $\mathrm{p}=0.96)$. No significant differences in secondary efficacy outcomes were observed. The mean plasma FG was unchanged after 2 hours in the FC group and decreased by $0.56 \mathrm{~g} / \mathrm{L}$ in the placebo group. No thromboembolic or other relevant adverse effects were reported in the FC group, versus two in the placebo group. Conclusions: Early and systematic administration of $3 \mathrm{~g}$ fibrinogen concentrate did not reduce blood loss, transfusion needs, and postpartum anaemia, but prevented plasma fibrinogen decrease without any subsequent thromboembolic events.
\end{abstract}

\section{Tweet:}


Early systematic $3 \mathrm{~g}$ fibrinogen infusion in PPH was safe, reduced hypofibrinogenemia but not anaemia and/or transfusion need.

\section{Introduction}

Postpartum haemorrhage (PPH) affects up to $10 \%$ of all deliveries, with a trend towards the incidence increasing over time in developed countries ${ }^{1,2}$. It is the leading cause of maternal mortality worldwide and accounts for up to $75 \%$ of severe maternal morbidity ${ }^{3}$. Multidisciplinary PPH management requires early diagnosis, identification of the underlying aetiology, rapid resuscitation, and medical and surgical treatment 4,5 .

Acquired coagulopathy is a major aggravating factor of blood loss ${ }^{6,7}$. During PPH, plasma fibrinogen is the first coagulation factor to drop precipitously due to bleeding, hyperfibrinolysis (consumption), and haemodilution ${ }^{8}$. Additionally, fibrinogen is an early biomarker for worsening of $\mathrm{PPH}$. The risk of progression to severe PPH increases almost 3 fold for each $1 \mathrm{~g} / \mathrm{L}$ decrease in fibrinogen concentration, and a positive predictive value of $100 \%$ for progression to severe $\mathrm{PPH}$ is observed with fibrinogen concentrations under $2 \mathrm{~g} / \mathrm{L}^{9-12}$.

Fibrinogen replacement therapy for severe bleeding has therefore gained popularity ${ }^{13-15}$. A multidisciplinary task force for advanced bleeding care in PPH patients recommends fibrinogen replacement if plasma level drops below $2 \mathrm{~g} / \mathrm{L}^{16}$. However, it remains debated whether systematic fibrinogen administration at an earlier stage may be helpful ${ }^{17,18}$, namely before plasma level determination. We therefore designed the FIDEL study based on the hypothesis that early and systematic treatment with a significant amount of fibrinogen concentrate $(3 \mathrm{~g})$ could reduce the need for red blood cell transfusion (to less than 2 RBC units) in PPH patients requiring a switch from oxytocin to prostaglandins and/or would limit postpartum haemoglobin decreases 48 hours after delivery to less than $4 \mathrm{~g} / \mathrm{dL}$.

\section{Methods}

\section{Study Design and Study Population}

FIDEL (FIbrinogen in DELivery) is a randomized, multicentre, double-blind, placebo-controlled study on the efficacy and safety of a therapeutic strategy comparing early and systematic administration of human fibrinogen versus placebo in patients with PPH when switched from intravenous oxytocin to prostaglandins following vaginal delivery. The full study protocol is available in Supplement 1. The initial protocol was published in $2016{ }^{19}$. The study was sponsored and funded by the company LFB (Les Ulis, France), which holds the marketing authorization for Clottafact $\AA$ (fibrinogen concentrate). The double-blind versus placebo research, data collection and results interpretation were conducted by an independent organism (Euraxi France) under the closed oversight of the scientific committee and the independent monitoring committee.

The FIDEL study was conducted in 30 public or private tertiary care hospitals in France. Subjects meeting the following main inclusion criteria (age [?] 18 years, with PPH following vaginal delivery requiring continuous intravenous prostaglandin administration (sulprostone, at an initial rate of $500 \mu \mathrm{g} / \mathrm{h}$, according to guidelines ${ }^{16}$ ), with at least one haemoglobin $(\mathrm{Hb})$ value available for the third trimester of pregnancy) were included and randomized. The other inclusion and non-inclusion criteria were described previously ${ }^{19}$. Given the emergency context, consent was obtained after brief delivery of information to the patient, or a relative or reliable person, depending on the patient's level of consciousness. In all cases, as soon as possible, the patient was fully informed about the study and asked to sign a post-inclusion consent form to continue participating.

\section{Funding :}

The study was sponsored and funded by the company LFB (Les Ulis, France), which holds the marketing

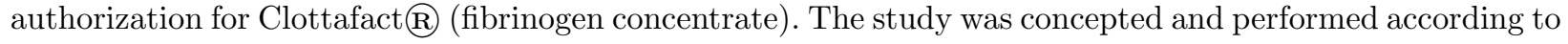
a double blind versus placebo design. Conception conduct of the study, quality assessment, data-management, blinded data validation, statistical management quality and paper writing were conducted under the oversight 
of the scientific committee. The awarded grant included external peer review for data collection,applicable regulation and scientific quality.

\section{PPH protocol}

The patients were managed medically and surgically according to the most recent French guidelines ${ }^{4,20,21}$. Antifibrinolytic prophylaxis was given according to the investigators' choice in both groups. Administration of tranexamic acid (TXA) or fibrinogen within $48 \mathrm{~h}$ prior to inclusion was a non-inclusion criteria, but was allowed after inclusion ${ }^{19}$. After intravenous infusion of the investigational medicinal product (IMP: $3 \mathrm{~g}$ fibrinogen concentrate or placebo), the decision to transfuse blood or not was taken based on European guidelines ${ }^{22}$. Administration of fibrinogen concentrate (Clottafact@, LFB, Les Ulis - France) beyond 60 minutes after the start of the IMP and of other rescue procedures were allowed as safety measures following strict rules to control bias ${ }^{19}$. The start time of the IMP infusion corresponded to H0. Blood samples were taken at H0, H2, H6 and D2 (Figure S1). The fibrinogen dose was set according to a preliminary kinetics study.

\section{Objectives and Endpoints}

The primary objective was to assess the benefits of early administration of fibrinogen for PPH management and reduction of bleeding after initiation of a sulprostone intravenous infusion. The primary efficacy criterion was a composite failure endpoint defined as loss of at least $4 \mathrm{~g} / \mathrm{dL}$ of $\mathrm{Hb}$ and/or need for transfusion of at least 2 units of packed red blood cells (RBCs) within the 48 hours following the IMP infusion. The Hb reference level was the most recent $\mathrm{Hb}$ value recorded in the third trimester of pregnancy (to get rid of the influence of initial haemorrhage).

The secondary objectives were to assess the evolution of haemorrhage and its management by further haemostatic interventions, as well as the safety of fibrinogen administration via adverse events collection ${ }^{19}$.

Study data were collected prospectively, from the day of delivery until the end of follow-up at $6 \pm 2$ weeks 19 .

\section{Randomization and Blinding}

Patients were randomized in a 1:1 ratio to either the fibrinogen or placebo groups in a double-blind manner. Randomization was stratified per centre with a block size of 4; IMP containers were sequentially numbered according to the computer-generated randomization sequence. Reconstitution of fibrinogen and formulation of the placebo ( 2 vials $=3 \mathrm{~g}$ of fibrinogen or placebo per patient) were carried out by trained research personnel not involved in the patients' care. Blinding of care providers and patients was maintained throughout by use of a masking system and tinted tubing. Each vial of fibrinogen concentrate $(1.5 \mathrm{~g})$ and placebo was reconstituted in $100 \mathrm{~mL}$ of sterile water and administered at a flow rate [?] $20 \mathrm{~mL} / \mathrm{min}$ within $30 \mathrm{~min}$ following the start of the sulprostone infusion.

\section{Sample Size Determination}

Failure rates of $42 \%$ and $27 \%$ were expected in the placebo and the fibrinogen groups, respectively, i.e. corresponding to a $15 \%$ absolute difference ${ }^{19}$. Assuming a $5 \%$ drop-out rate due difficulties to collect data in emergency conditions, 434 patients needed to be enrolled to achieve a power of $90 \%$ at the 2 -sided significance level of 0.05 . As there was uncertainty about expected rates which impacted the variance of the failure rate difference, a blinded interim analysis to reassess sample size to maintain a power of $90 \%$ led to a sample size increase from 434 to 470 patients. Given the lower than expected drop-out rate of $1.55 \%$, the trial was stopped on June 30, 2018 with 448 patients enrolled and a trial power of 89.6\%.

\section{Statistical Analysis}

Analyses were conducted with SAS(r) software (version 9.4.). The primary analysis was performed with the intention-to-treat (ITT) set, i.e. all randomized patients who received at least one dose of IMP. The primary endpoint was analysed using a logistic regression model with adjustments for treatment, baseline fibrinogen 
levels (categorized as [?] 2, ]2;3], ]3,4], > $4 \mathrm{~g} / \mathrm{L}$ ) and centre (23 centres that enrolled less than 20 patients were pooled as one centre). The treatment effect was estimated as an odds ratio (OR) along with its $95 \%$ Confidence Interval $(95 \% \mathrm{CI})$ and tested with the Wald test at the 0.05 significance level. An OR below 1 indicated a lower failure risk in the fibrinogen group compared to the control group. Missing data were not replaced in the primary analysis. Sensitivity analyses for handling missing data were performed. Another supportive analysis was performed on the per-protocol (PP) set.

Changes in plasma fibrinogen levels from IMP administration to 2 hours (H2), 6 hours (H6) and 2 days (D2) were analysed in a Mixed Model for Repeated Measurements (MMRM). For continuous secondary efficacy endpoints, treatment groups were compared with a t-test or a Wilcoxon test, and binary endpoints were compared with a Pearson Chi-square test or a Fisher exact test. All p-values provided for secondary efficacy endpoints are for exploratory purposes only. No adjustments were made for multiple comparisons.

\section{Results}

\section{Patients and PPH Characteristics}

From April 2014 to August 2018, 448 patients suffering from PPH were eligible for the study. After initial screening, 443 patients were randomized; 437 received the IMP and were retained in the ITT population of which 224 in the fibrinogen group and 213 in the placebo group (Figure 1).

Baseline characteristics did not differ between the two groups (Table 1 and Table S2). The predominant cause of haemorrhage was uterine atony $(82 \%)$. The mean $\mathrm{Hb}$ value $(+-\mathrm{SD})$ at $\mathrm{H} 0$ was $10.9+-1.5 \mathrm{~g} / \mathrm{dL}$. Total mean estimated blood loss (+- SD) was $877+-346 \mathrm{~mL}$ at the start of prostaglandin administration. Tranexamic acid was administered after inclusion to $48 \%$ of patients (median dose: $1 \mathrm{~g}$; range: $0.5-2 \mathrm{~g}$ ).

\section{Primary Outcome}

The failure rates were similar in the fibrinogen and placebo groups, i.e. $40.0 \%$ versus $42.4 \%$, respectively. Logistic regression analysis showed no significant between-group difference: OR=0.99 (95\%CI: [0.66;1.47]; $\mathrm{p}=0.96)$. The planned sensitivity analyses yielded similar results.

\section{Secondary Outcomes and Exploratory Analyses}

Bleeding was controlled in all cases, with mean total blood losses in the fibrinogen and placebo groups of 1555 and $1723 \mathrm{~mL}$, respectively $(\mathrm{p}=0.21)$. There were no maternal deaths (Table 2 ). The two components of the composite primary endpoint were analysed separately. Transfusion rates (proportion of patients who had more than 2 RBC units) were similar in the fibrinogen and placebo groups $(23.4 \%$ versus $25.0 \%$; OR $=1.01$; $\mathrm{p}=0.98$ ). Similarly, the proportion of patients with $\mathrm{Hb}$ drops $>4 \mathrm{~g} / \mathrm{dL}$ on $\mathrm{D} 2$ compared with the reference value were identical in the fibrinogen and placebo groups, i.e. $19.1 \%$ and $19.5 \%$, respectively $(\mathrm{OR}=1.02$; $\mathrm{p}=0.95)$.

All patient characteristics, PPH management actions, transfusion outcomes, and haemostatic rescue procedures are shown in Supplement 2, Table S1 and Table S4. There were no between-group differences in secondary outcomes (Table 2) or recorded adverse events (Table S5) in either the ITT or PP populations.

Total blood loss $>1000 \mathrm{~mL}$ and $\mathrm{Hb}$ loss $>2 \mathrm{~g} / \mathrm{dL}$ and plasma fibrinogen level [?] $4 \mathrm{~g} / \mathrm{L}$ were identified as significant baseline predictive factors of failure as per the composite primary endpoint (multivariate analysis). Conversely, the centre, a baseline heart rate $>100$ beats per minute (bpm) and baseline TXA administration were not. Some post-randomization variables were also significantly associated with an excess risk of failure: fresh frozen plasma transfusion, the need for a rescue procedure and a heart rate $>100 \mathrm{bpm}$ (Table S3). However, adjustment of the effect of IMP supplementation on those variables demonstrated no betweengroup differences either (not shown). The number of subjects with initial fibrinogen concentrations [?] $2 \mathrm{~g} / \mathrm{L}$ was too small $(n=5)$ to assess a treatment effect in this subgroup of patients.

At baseline, the plasma fibrinogen concentration was $4.1+-0.9 \mathrm{~g} / \mathrm{L}$ with no between-group difference. Around $11 \%$ of patients had fibrinogen levels [?] $3 \mathrm{~g} / \mathrm{L}$, including $1 \%$ whose levels were [?] $2 \mathrm{~g} / \mathrm{L}$ (Table 
1). Following administration of $3 \mathrm{~g}$ fibrinogen concentrate, mean plasma fibrinogen concentrations were 4.2 +- $0.8 \mathrm{~g} / \mathrm{L}$ at $\mathrm{H} 2$, and $5.1+-0.9 \mathrm{~g} / \mathrm{L}$ on $\mathrm{D} 2$. By contrast, the fibrinogen concentration decreased in the placebo group at $\mathrm{H} 2(3.5+-0.8 \mathrm{~g} / \mathrm{L})$ and remained lower than in the fibrinogen group on D2 $(4.6+-0.8$ $\mathrm{g} / \mathrm{L}$ ) (Figure 2). The mean change between baseline and $\mathrm{H} 2$ was $+0.03+-0.69 \mathrm{~g} / \mathrm{L}$ in the fibrinogen group and $-0.56+-0.56 \mathrm{~g} / \mathrm{L}$ in the placebo group. The MMRM showed a treatment-time interaction $(\mathrm{p}=0.023)$, indicating that the overall plasma fibrinogen level time-course was different between the two groups.

Longitudinal analysis of $\mathrm{Hb}$ concentration and haematocrit showed significant decreases during the first 48 hours compared with baseline, but no time-course differences between the two groups (not shown).

\section{Concomitant treatments and invasive procedures}

Tranexamic acid (median dose: $3 \mathrm{~g}$; range: 1.5-6) was administered to $65 \%$ of patients as rescue therapy, after IMP administration, with no significant between-group differences (Table S1). At least one fibrinogen concentrate $(1.5 \mathrm{~g})$ was administered as rescue therapy to $4.0 \%$ of patients in the fibrinogen group, and $8.0 \%$ in the placebo group $(\mathrm{p}=0.080)$. Intrauterine balloon was used in $29 \%$ of patients with no between-group differences, but the need for invasive haemostatic procedures (mainly arterial embolization) remained rare (3.6\% and $4.8 \%$ in the fibrinogen and placebo groups, respectively; $\mathrm{p}=0.56)$. All patients received crystalloids after baseline (median volume: $2000 \mathrm{~mL}$ ), and $28 \%$ received hydroxyethyl starch (median volume: $500 \mathrm{~mL}$ ) with no between-group differences. Blood products were also used with no between-group differences with $25 \%$ of patients having received RBCs (median: 2 units), 10\% fresh frozen plasma (median: 2 units), and $1.6 \%$ platelets (median: 3 units).

\section{Safety}

Two patients in the placebo group experienced a thromboembolic event, while no such events were reported in the fibrinogen group (Table S5). The proportion of patients with severe morbidity requiring intensive care or resuscitation was similar in both groups (Table 2), and organ failure was rare (2 patients in each group had a SOFA score [?] 3).

\section{Discussion}

\section{Main findings}

FIDEL is the largest randomized, double-blind, placebo-controlled, multicentre trial conducted to date to assess the value of early and systematic fibrinogen supplementation $(3 \mathrm{~g})$ in PPH patients requiring prostaglandin administration following vaginal delivery. Despite the large study size, we failed to demonstrate an effect of the strategy on transfusion requirements and/or postpartum anaemia, total blood loss, or the need for balloon tamponade or invasive haemostatic procedures. Our study results are in agreement with those of two other recent randomized studies: FIB-PPH, conducted in Denmark ${ }^{24}$ and OBS2, conducted in the United Kingdom (UK) ${ }^{17}$. No thromboembolic or any other relevant undesirable events were recorded in the fibrinogen group, underlining that early administration of $3 \mathrm{~g}$ fibrinogen concentrate appears safe in this context.

\section{Strengths and limitations}

The main selection criterion was PPH following vaginal delivery requiring uterotonic prostaglandin administration as per French guidelines ${ }^{17,24}$. The hypothesis was that patients with persistent PPH would present a significant decrease in plasma fibrinogen levels. We therefore expected that these patients would benefit from early fibrinogen supplementation, before their plasma fibrinogen level results became available. However, we could not to recruit enough patients with an ongoing coagulopathy (as shown by changes in plasma fibrinogen levels in Figure 2) and in whom fibrinogen concentrate was expected to be beneficial. We encountered similar issues to those reported in the Danish and UK studies ${ }^{17,24}$. This is partly due to the difficulty of including and obtaining informed consent from subjects with massive and rapid ongoing bleeding.

Moreover, the globally improved management of $\mathrm{PPH}$, at least in developed countries, also explains why the FIDEL study failed to demonstrate any benefit from early systematic fibrinogen administration. Nowa- 
days, management not only involves timely decision-making shared by obstetricians and anaesthesiologists, but also the early use of TXA and intrauterine balloon tamponade, routinely applied after prostaglandin administration ${ }^{5,7,25,26}$. Following a pragmatic approach to optimize their security (including the possibility of administering rescue fibrinogen in both groups), all patients were treated with standard procedures as per guidelines and as decided by the investigators. We may have in fact correctly selected and randomized patients at risk for severe PPH, but at a very early stage. Postpartum haemorrhage was rapidly controlled and, in most cases, with no significant hemodynamic disorders, no coagulopathy, and subsequently normal fibrinogen levels. Very few invasive haemostatic procedures were required, and the quite common use of balloon tamponade in both groups $(29 \%)$ may be regarded as an evolution of practices that dramatically reduces embolization and hysterectomy rates ${ }^{27}$. This change occurred during the course of the FIDEL study.

Recruitment of potentially severe but rapidly controlled PPH (due to a strong incentive to include patients as early as possible), and optimized management are the main likely explanations for the absence of a fibrinogen supplementation effect. Our protocol did not include waiting for plasma fibrinogen assay results prior to IMP administration. By contrast, older studies reported substantial delays from inclusion to measurement of plasma fibrinogen prior to fibrinogen administration during which important blood loss and haemodilution occurred, and fibrinogen levels dropped significantly ${ }^{9,11}$. We therefore failed to demonstrate a benefit from the "pre-emptive" administration of fibrinogen to patients at risk of severe PPH.

\section{Interpretation}

Interestingly, in the OBS2 study, fibrinogen was administered after immediate estimation of fibrinogen levels using the Rotem? viscoelastomeric point-of-care test ${ }^{17}$. A nearly two-fold decrease in total allogenic blood product transfusion rate was observed in women with plasma fibrinogen concentrations estimated below $2.0 \mathrm{~g} / \mathrm{L}$ and supplemented with fibrinogen. The difference was not significant however due to a lack of power. Our study and its negative results further contributes to the attractiveness of rapid plasma fibrinogen assays for initiating and guiding treatment when necessary,i.e. only in the most severe cases associated with coagulopathy and low fibrinogen levels ${ }^{15}$.

Thus, three major randomized and well conducted controlled studies, FIB-PPH, OBS2 and FIDEL, all found that early fibrinogen replacement is not beneficial in the course of severe PPH management when a second line uterotonic agent is needed after prostaglandins and when plasma fibrinogen level is not known. Nonetheless, several other and older observational studies or reports from the UK, Japan, or Turkey still maintain that fibrinogen supplementation is effective and beneficial ${ }^{14,28-32}$. This is not surprising, as most patients in those studies presented very severe and advanced PPH, and much greater blood loss and much lower plasma fibrinogen concentrations (usually $<1 \mathrm{~g} / \mathrm{L}$ ) than those reported in the randomized studies. Although the patients received numerous transfusions (including fresh frozen plasma, FFP) and were not compared with adequate control groups, the studies documented safety and established the usefulness of massive doses of fibrinogen (up to $8 \mathrm{~g}$ ) to avoid FFP transfusion, fluid overload, and for rapid correction of very low fibrinogen levels. Although the randomized controlled trial is the gold standard methodology for demonstrating the efficacy of a therapeutic strategy, it is not always adapted to field constraints, especially in life-threatening emergencies. In light of this, observational or uncontrolled studies provide potentially biased, but better targeted data, which are truly informative and complementary to those of randomized controlled trials.

Altogether, these studies back the use of a targeted strategy to adjust the supplementation to the fibrinogen level estimation. Because fibrinogen decrease may be drastic in $\mathrm{PPH}{ }^{33,34}$, and because a prompt therapeutic answer is expected, newly available "plug-and-play" viscoelastometry bedside devices allowing a quick and convenient assay in the emergency room are very useful tools. This approach can help clinicians identify coagulopathies in "real-time" and when emergency fibrinogen supplementation is required, especially in severe cases of PPH, or in specific situations such as placental abruption or amniotic fluid embolism ${ }^{33,34}$.

\section{Conclusion}

In patients with $\mathrm{PPH}$ requiring prostaglandins after vaginal delivery, a strategy consisting in administering 
$3 \mathrm{~g}$ fibrinogen concentrate prior to determination of plasma fibrinogen levels as a systematic adjuvant to standard care, did not reduce blood loss, transfusion needs, and postpartum anaemia, but prevented plasma fibrinogen decreases without generating any subsequent thromboembolic events.

\section{Acknowledgements}

Special thanks to the medical teams of all the investigational centres and the patients without whom the study could not have been conducted. The sponsor (LFB - Les Ulis, France) supervised all the tasks related to the study: study design and conduct, including the supply of IMPs; the collection, management, analysis, and interpretation of data; preparation, review, or approval of the manuscript; and decision to submit the manuscript for publication. Nathalie Dinouel and Eric-Olivier Jaudinot contributed significantly to the study as the sponsor's project manager and the sponsor's senior manager, respectively. The contract research organization Euraxi Pharma (Joue-les-Tours, France) was appointed by the sponsor to coordinate the study. The authors especially thank Virginie Martin (overall project management), Frederique Leger (data management), Benoit Berge (statistics), Odile Capronnier (medical writing), and the Euraxi's monitoring team for their contribution to the FIDEL study.

\section{Disclosure of interests}

ASB, FJM, AM, CH and JMG received fees from LFB as members of the FIDEL trial Scientific Committee. FJM also received fees from LFB for symposium lectures. FBr and FV received fees from LFB as FIDEL investigators. ALG, FV and FBa received fees from LFB for dispensing medical training. FBr and AL were invited by LFB to a congress. TB received fees from LFB for a work of expert.

\section{Contribution to autorship}

All authors contributed substantially to the work, provided important intellectual content, had full access to data and had the final responsibility for the decision to submit for publication. ASB (coordinating investigator) had full access to all the data in the study and takes responsibility for the integrity of the data and the accuracy of the data analysis. All members of the scientific committee (ASB, FJM, AM, $\mathrm{CH}$ and JMG) participated actively in the trial design, the monitoring of inclusions, data validation, data analysis and interpretation; they also demonstrated strong commitment to informing and motivating the study investigators throughout the trial. All investigators (FB,JC,AL,TR,FB,FV,AL and FIDEL Working group investigators) contributed actively to the inclusions, their monitoring, data validation and analysis.

\section{Ethics approval}

The FIDEL study was conducted in accordance with the principles of the Helsinki Declaration and its subsequent amendments and Good Clinical Practices (CPMP/ICH/135/95). It was approved by an independent French Ethics Committee (Comite de Protection des Personnes Nord Ouest IV , approval given on December 10, 2013) as required by French law ${ }^{19,23}$.

The research was also submitted to the French Regulatory Agency (Agence Nationale de Securite du Medicament et des produits de sante ). Authorisation was given on November 25, 2013.

Given the emergency context, consent to participate was obtained after brief delivery of information to the patient, or a relative or reliable person, depending on the patient's level of consciousness. In all cases, as soon as possible, the patient was fully informed about the study and asked to sign a post-inclusion consent form to continue participating.

The FIDEL study was registered in the European and US trial databases under Eudract No. 2013-002484-26 and NCT02155725, respectively.

\section{Funding}

The study was sponsored and funded by the company LFB (Les Ulis, France), which holds the marketing authorization for Clottafact(r) (fibrinogen concentrate). 


\section{Consent to participate}

Given the emergency context, consent to participate was obtained after brief delivery of information to the patient, or a relative or reliable person, depending on the patient's level of consciousness. In all cases, as soon as possible, the patient was fully informed about the study and asked to sign a post-inclusion consent form to continue participating.

\section{Availability of data}

The data that support the findings of this study are available from the corresponding author upon reasonable request.

\section{References}

1. Knight M, Callaghan WM, Berg C et al. Trends in postpartum hemorrhage in high resource countries: a review and recommendations from the International Postpartum Hemorrhage Collaborative Group. BMC Pregnancy Childbirth . 2009;9:55.

2. Kramer MS, Berg C, Abenhaim $\mathrm{H}$ et al. Incidence, risk factors, and temporal trends in severe postpartum hemorrhage. Am J Obstet Gynecol . 2013;209(5):449 e1-7.

3. Say L, Chou D, Gemmill A et al. Global causes of maternal death: a WHO systematic analysis. Lancet Glob Health . 2014;2(6):e323-33.

4. Sentilhes L, Vayssiere C, Mercier FJ et al. [Postpartum hemorrhage: Guidelines for clinical practice Text of the Guidelines (short text)]. J Gynecol Obstet Biol Reprod . 2014;43(10):1170-1179.

5. Ring L, Landau R. Postpartum hemorrhage: Anesthesia management. Semin Perinatol . 2019;43(1):3543.

6. Collis RE, Collins PW. Haemostatic management of obstetric haemorrhage. Anaesthesia . 2015;70 Suppl 1:78-86, e27-8.

7. Ducloy-Bouthors AS, Susen S, Wong CA et al. Medical advances in the treatment of postpartum hemorrhage. Anesth Analg . 2014;119(5):1140-7.

8. Butwick AJ. Postpartum hemorrhage and low fibrinogen levels: the past, present and future. Int J Obstet Anesth . 2013;22(2):87-91.

9. Charbit B, Mandelbrot L, Samain E et al. The decrease of fibrinogen is an early predictor of the severity of postpartum hemorrhage.J Thromb Haemost . 2007;5(2):266-73.

10. Cortet M, Deneux-Tharaux C, Dupont C et al. Association between fibrinogen level and severity of postpartum haemorrhage: secondary analysis of a prospective trial. Br J Anaesth . 2012;108(6):984-9.

11. Gayat E, Resche-Rigon M, Morel O et al. Predictive factors of advanced interventional procedures in a multicentre severe postpartum haemorrhage study. Intensive Care Med . 2011;37(11):1816-25.

12. Collins PW, Lilley G, Bruynseels D et al. Fibrin-based clot formation as an early and rapid biomarker for progression of postpartum hemorrhage: a prospective study. Blood . 2014;124(11):1727-36.

13. Ahmed S, Harrity C, Johnson S et al. The efficacy of fibrinogen concentrate compared with cryoprecipitate in major obstetric haemorrhage-an observational study. Transfus Med . 2012;22(5):344-9.

14. Makino S, Takeda S, Kobayashi $\mathrm{T}$ et al. National survey of fibrinogen concentrate usage for postpartum hemorrhage in Japan: investigated by the Perinatology Committee, Japan Society of Obstetrics and Gynecology. J Obstet Gynaecol Res . 2015;41(8):1155-60.

15. Mallaiah S, Barclay P, Harrod I, Chevannes C, Bhalla A. Introduction of an algorithm for ROTEM-guided fibrinogen concentrate administration in major obstetric haemorrhage. Anaesthesia . 2015;70(2):166-75. 
16. Munoz M, Stensballe J, Ducloy-Bouthors AS et al. Patient blood management in obstetrics: prevention and treatment of postpartum haemorrhage. A NATA consensus statement. Blood Transfus . 2019;17(2):112136.

17. Collins PW, Cannings-John R, Bruynseels D et al. Viscoelastometric-guided early fibrinogen concentrate replacement during postpartum haemorrhage: OBS2, a double-blind randomized controlled trial. $\mathrm{Br} J$ Anaesth . 2017;119(3):411-421.

18. Wikkelso AJ. The role of fibrinogen and haemostatic assessment in postpartum haemorrhage: preparations for a randomised controlled trial. Dan Med J . 2015;62(4):B5055.

19. Ducloy-Bouthors AS, Mignon A, Huissoud C, Grouin JM, Mercier FJ. Fibrinogen concentrate as a treatment for postpartum haemorrhage-induced coagulopathy: A study protocol for a randomised multicentre controlled trial. The fibrinogen in haemorrhage of DELivery (FIDEL) trial.Anaesth Crit Care Pain Med . 2016;35(4):293-8.

20. HAS, Hemorragies du post-partum immediat, inRecommandations pour la pratique clinique . 2004, Haute Autorite de Sante: Paris.

21. Mercier FJ, Van de Velde M. Major obstetric hemorrhage.Anesthesiol Clin . 2008;26(1):53-66, vi.

22. Kozek-Langenecker SA, Afshari A, Albaladejo P et al. Management of severe perioperative bleeding: guidelines from the European Society of Anaesthesiology. Eur J Anaesthesiol . 2013;30(6):270-382.

23. Toulouse E, Masseguin C, Lafont B et al. French legal approach to clinical research. Anaesth Crit Care Pain Med . 2018;37(6):607-614.

24. Wikkelso AJ, Edwards HM, Afshari A et al. Pre-emptive treatment with fibrinogen concentrate for postpartum haemorrhage: randomized controlled trial. Br J Anaesth . 2015;114(4):623-33.

25. Woman Trial Collaborators. Effect of early tranexamic acid administration on mortality, hysterectomy, and other morbidities in women with post-partum haemorrhage (WOMAN): an international, randomised, double-blind, placebo-controlled trial.Lancet . 2017;389(10084):2105-2116.

26. Vrachnis N, Salakos N, Iavazzo C et al. Bakri balloon tamponade for the management of postpartum hemorrhage. Int J Gynaecol Obstet . 2013;122(3):265-6.

27. Revert M, Rozenberg P, Cottenet J, Quantin C. Intrauterine Balloon Tamponade for Severe Postpartum Hemorrhage. Obstet Gynecol . 2018;131(1):143-149.

28. Bell SF, Rayment R, Collins PW, Collis RE. The use of fibrinogen concentrate to correct hypofibrinogenaemia rapidly during obstetric haemorrhage. Int J Obstet Anesth . 2010;19(2):218-23.

29. Glover NJ, Collis RE, Collins P. Fibrinogen concentrate use during major obstetric haemorrhage. Anaesthesia . 2010;65(12):1229-30.

30. Gollop ND, Chilcott J, Benton A et al. National audit of the use of fibrinogen concentrate to correct hypofibrinogenaemia. Transfus Med . 2012;22(5):350-5.

31. Kikuchi M, Itakura A, Miki A et al. Fibrinogen concentrate substitution therapy for obstetric hemorrhage complicated by coagulopathy. J Obstet Gynaecol Res . 2013;39(4):770-6.

32. Sahin AS, Ozkan S. Treatment of Obstetric Hemorrhage with Fibrinogen Concentrate. Med Sci Monit . 2019;25:1814-1821.

33. Bonnet MP, Zlotnik D, Saucedo M et al. Maternal Death Due to Amniotic Fluid Embolism: A National Study in France. Anesth Analg . 2018;126(1):175-182.

34. Pujolle E, Mercier FJ, Le Gouez A. Rotational thromboelastometry as a tool in the diagnosis and management of amniotic fluid embolism. Int J Obstet Anesth . 2019;38:146-147. 
Table 1: Baseline characteristics of the population

\begin{tabular}{|c|c|c|}
\hline Characteristics & Fibrinogen $\mathrm{N}=224$ & Placebo $\mathrm{N}=213$ \\
\hline Age, mean \pm SD, years & $30.5 \pm 5.6$ & $30.3 \pm 5.4$ \\
\hline $\begin{array}{l}\text { Weight before pregnancy, mean } \\
\pm \mathrm{SD}, \mathrm{kg}\end{array}$ & $65.2 \pm 13.9$ & $65.5 \pm 14.8$ \\
\hline $\begin{array}{l}\text { Weight (last known), mean } \pm \\
\text { SD, kg }\end{array}$ & $77.6 \pm 13.6$ & $77.8 \pm 13.7$ \\
\hline $\begin{array}{l}\text { Height, mean } \pm \mathrm{SD}, \mathrm{cm} \\
\text { Parity, N (\%) }\end{array}$ & $165.8 \pm 5.8$ & $165.8 \pm 6.5$ \\
\hline Primiparous & $113(50.4 \%)$ & $96(45.1 \%)$ \\
\hline Multiparous & $111(49.6 \%)$ & $117(54.9 \%)$ \\
\hline Multiple pregnancy, N (\%) & $25(11.2 \%)$ & $24(11.3 \%)$ \\
\hline Term, mean $\pm \mathrm{SD}$, weeks & $39.2 \pm 1.9$ & $38.9 \pm 2.3$ \\
\hline $\begin{array}{l}\text { Prepartum Hb level, mean } \pm \\
\text { SD, g/dL }\end{array}$ & $11.8 \pm 1.0$ & $11.9 \pm 0.9$ \\
\hline Induction of labor, N (\%) & $88(39.3 \%)$ & $65(30.5 \%)$ \\
\hline $\begin{array}{l}\text { Instrumental vaginal delivery, } \mathrm{N} \\
(\%)\end{array}$ & $54(24.1 \%)$ & $43(20.2 \%)$ \\
\hline \multicolumn{3}{|l|}{ Cause of PPH, N (\%) } \\
\hline Atony & $179(79.9 \%)$ & $182(85.4 \%)$ \\
\hline Placenta retention & $67(29.9 \%)$ & $52(24.4 \%)$ \\
\hline Lower genital tract wound & $19(8.5 \%)$ & $19(8.9 \%)$ \\
\hline Other & $8(3.6 \%)$ & $1(0.5 \%)$ \\
\hline \multicolumn{3}{|l|}{ Time from..., mean $\pm \mathrm{SD}$, min } \\
\hline Delivery to start of bleeding & $41.2 \pm 57.4$ & $38.5 \pm 58.4$ \\
\hline $\begin{array}{l}\text { Delivery to start of sulprostone } \\
\text { administration }\end{array}$ & $73.8 \pm 70.5$ & $74.7 \pm 116.5$ \\
\hline $\begin{array}{l}\text { Delivery to start of study drug } \\
\text { infusion }\end{array}$ & $92.0 \pm 70.8$ & $85.2 \pm 65.9$ \\
\hline \multicolumn{3}{|l|}{ Prior Tranexamic Acid } \\
\hline $\mathrm{N}(\%)$ & $107(47.8 \%)$ & $102(47.9 \%)$ \\
\hline Mean $\pm \mathrm{SD}, \mathrm{g}$ & $1.1 \pm 0.3$ & $1.1 \pm 0.3$ \\
\hline $\begin{array}{l}\text { Estimated blood loss at the } \\
\text { start of prostaglandin infusion, } \\
\text { mean (SD), mL }\end{array}$ & $896 \pm 373$ & $857 \pm 315$ \\
\hline $\begin{array}{l}\text { Plasma Fibrinogen level at } \\
\text { inclusion, mean } \pm \mathrm{SD}, \mathrm{g} / \mathrm{L} \\
\mathrm{N}(\%)\end{array}$ & $4.2 \pm 0.9$ & $4.0 \pm 1.0$ \\
\hline [?] $2 \mathrm{~g} / \mathrm{L}$ & $2(1.0 \%)$ & $3(1.5 \%)$ \\
\hline$] 2 ; 3] \mathrm{g} / \mathrm{L}$ & $19(9.1 \%)$ & $21(10.8 \%)$ \\
\hline ]3-4] g/L & $62(29.7 \%)$ & $75(38.5 \%)$ \\
\hline$>4 \mathrm{~g} / \mathrm{L}$ & $126(60.3 \%)$ & $96(49.2 \%)$ \\
\hline
\end{tabular}

Population: ITT set

Table 2: Primary and secondary outcomes 


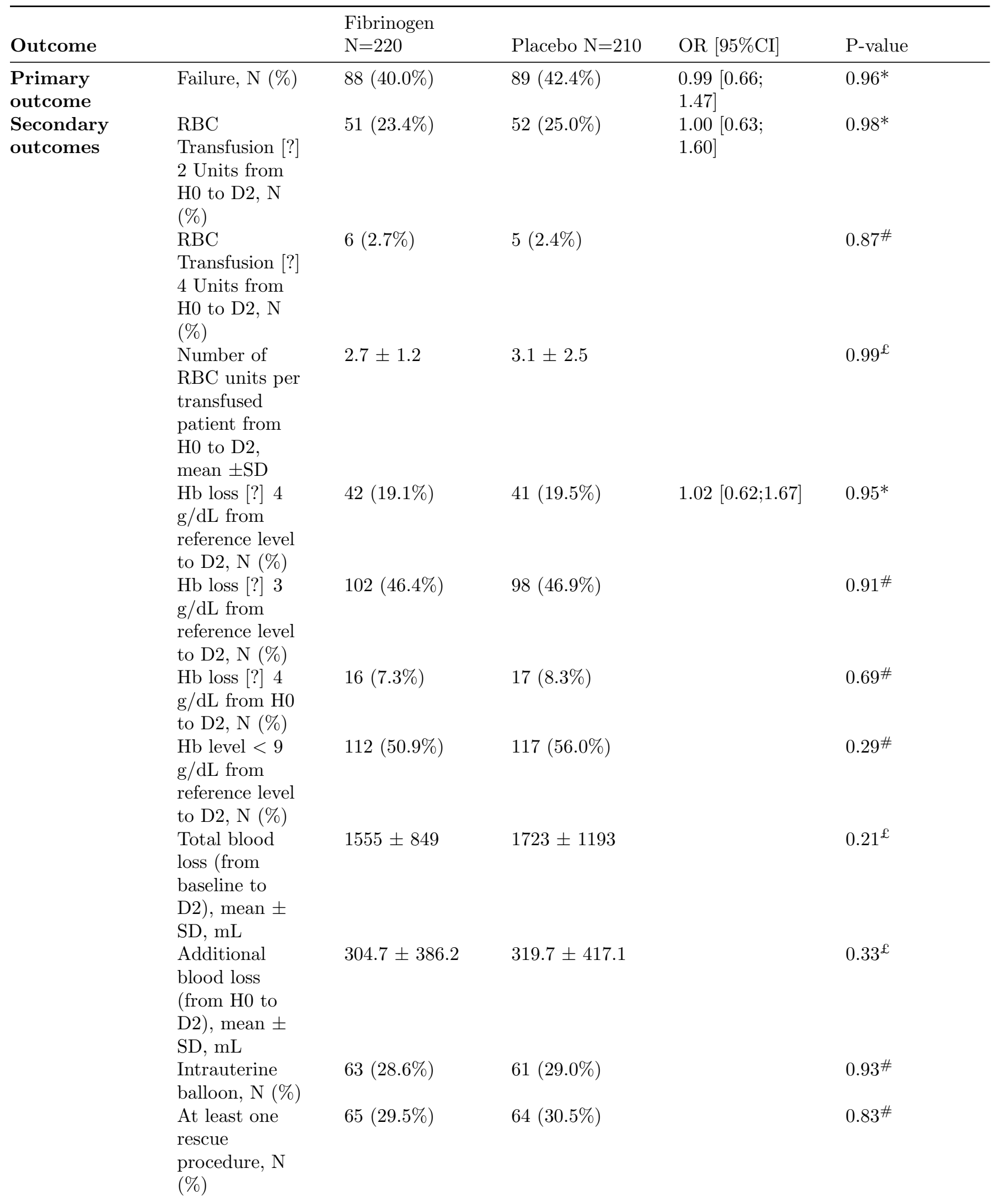




\begin{tabular}{|c|c|c|c|c|c|}
\hline \multicolumn{2}{|l|}{ Outcome } & \multicolumn{3}{|l|}{ Fibrinogen } & $\mathrm{P}$-value \\
\hline & $\begin{array}{l}\text { At least one } \\
\text { invasive }\end{array}$ & $8(3.6 \%)$ & $10(4.8 \%)$ & & $0.56^{\#}$ \\
\hline & $\begin{array}{l}\text { hemostatic } \\
\text { procedure, } \mathrm{N} \\
\text { (\%), including: }\end{array}$ & & & & \\
\hline & $\begin{array}{l}\text { Arterial } \\
\text { embolization }\end{array}$ & $6(2.7 \%)$ & $10(4.8 \%)$ & & $0.27 \#$ \\
\hline & $\begin{array}{l}\text { Arterial } \\
\text { ligation }\end{array}$ & $0(0 \%)$ & $0(0 \%)$ & & - \\
\hline & Hysterectomy & $0(0 \%)$ & $1(0.5 \%)$ & & $0.49^{\$}$ \\
\hline & $\begin{array}{l}\text { Intensive care } \\
\text { or } \\
\text { resuscitation, } \\
\mathrm{N}(\%)\end{array}$ & $62(28.2 \%)$ & $54(25.7 \%)$ & & $0.56^{\#}$ \\
\hline & $\begin{array}{l}\text { Length of stay } \\
\text { in intensive } \\
\text { care or } \\
\text { resuscitation } \\
\text { unit, mean } \pm \\
\text { SD, day }\end{array}$ & $0.7 \pm 0.6$ & $0.7 \pm 0.9$ & & $0.84^{£}$ \\
\hline & $\begin{array}{l}\text { SOFA score of } \\
\text { patients } \\
\text { admitted to } \\
\text { intensive care } \\
\text { or } \\
\text { resuscitation } \\
\text { unit, median } \\
\text { [min; max] }\end{array}$ & $0[0 ; 4]$ & $0[0 ; 6]$ & & $0.32^{£}$ \\
\hline & Death, N (\%) & $0(0 \%)$ & $0(0 \%)$ & & - \\
\hline
\end{tabular}

The primary efficacy outcome variable is a composite endpoint of failure, defined as a patient:

*having lost at least $4 \mathrm{~g} / \mathrm{dL}$ of $\mathrm{Hb}$ compared to the reference $\mathrm{Hb}$ level within the 48 hours following investigational medicinal product (IMP) administration,

AND/OR

*requiring transfusion of at least 2 units of packed RBCs within 48 hours following the administration of the IMP.

Reference $\mathrm{Hb}$ value: last value measured during the $3^{\text {rd }}$ trimester of pregnancy

Population: ITT set with no missing data for the primary criterion

* Wald test for treatment effect (Placebo is the reference class), as per the logistic regression adjusted on center and baseline fibrinogen; \# Chi-square test; £ Wilcoxon Mann-Whitney test; $\$$ Fisher exact test.

\section{Figure Legends}

Figure 1: Patient flow through the trial

Primary and secondary outcomes were analysed on the ITT set with no missing data for the primary criterion, i.e. 430 patients (220 in the Fibrinogen group and 210 in the Placebo group) 
Figure 2: Mean fibrinogen concentrations in Fibrinogen and Placebo groups from baseline to D2 after study drug administration (ITT set with no missing data for the primary criterion)

Values: mean. Error bars: SD (presented one-sided instead of two-sided for readability purposes only)

The mixed model for repeated measures showed a treatment ${ }^{*}$ time interaction, with an overall p-value=0.023.

Hosted file

BJOG_FIDEL_Figure 1.docx available at https://authorea.com/users/355339/articles/478625early-and-systematic-administration-of-fibrinogen-concentrate-in-postpartum-haemorrhagefollowing-vaginal-delivery-the-fidel-randomized-controlled-trial

\section{Hosted file}

BJOG_FIDEL_Figure 2.docx available at https://authorea.com/users/355339/articles/478625early-and-systematic-administration-of-fibrinogen-concentrate-in-postpartum-haemorrhagefollowing-vaginal-delivery-the-fidel-randomized-controlled-trial 